\title{
Formação inicial em Educação Física: uma nova epistemologia da prática docente
}

\author{
Ieda Parra Barbosa-Rinaldi*
}

\begin{abstract}
Resumo: Pretendemos refletir sobre a necessidade dos docentes, que atuam na formação de professores em Educação Física, em romper com o paradigma técnico-instrumental, rumo a uma nova epistemologia da prática docente. Inicialmente estabelecemos um debate sobre o processo de proletarização do ensino que alimenta a dificuldade em se romper com o paradigma dominante presente na formação docente. Após, buscamos compreender a necessidade de mudanças e as possibilidades de uma prática reflexiva no trato com o conhecimento na formação de professores.
\end{abstract}

Palavras-chave: Docentes. Ensino. Conhecimento.

\section{INTRODUÇÃO}

Atualmente, temos nos deparado, cada vez com mais freqüência, com depoimentos e/ou questionamentos de docentes do ensino superior sobre quais conhecimentos deveriam estar presentes na formação inicial e principalmente como tratá-los. De acordo com Barbosa-Rinaldi e Martineli (2003), estes podem ser visualizados nas publicações e nas discussões e reflexões presentes nos principais eventos nacionais da área ou, ainda, nos embates que surgiram durante o processo de reestruturação curricular pelo qual passaram os cursos de educação física de todo território nacional nos últimos anos. Isso demonstra a preocupação dos pesquisadores em levantar problemas e apontar caminhos no sentido da intervenção, porque se reconhece a necessidade de mudanças.

Historicamente, é possível observar que a partir dos anos de 1980, estudiosos da área de Educação Física voltaram-se para essa problemática na tentativa de buscar uma nova postura para o ensino

\footnotetext{
* Professora Doutora do Departamento de Educação Física da Universidade Estadual de
} Maringá, PR. Brasil. E-mail: parrarinaldi@hotmail.com 
superior, entendendo que o período de formação inicial é importante, pois é nele que se adquirem conhecimentos indispensáveis para a atuação profissional. É o momento em que os futuros professores poderão, ou não, alterar a concepção que possuem de Educação Física, assumirão, ou não, uma prática pedagógica permeada pela cultura dominante. Neste período, a comunidade acadêmica da Educação Física mobilizou-se para oferecer uma formação coerente com as aspirações da sociedade brasileira e, indiscutivelmente, essas mudanças foram necessárias, mas as discussões sobre a formação profissional continuam sendo temáticas atuais, haja vista a preocupação presente nos estudos sobre o processo de formação de professores de Educação Física (BETTI,1992; PALMA, 2001; MARTINELI, 2001; RIBEIRO, 2003, dentre outros). Evidencia-se, ainda hoje, o paradigma hegemônico, a racionalidade técnica ou tecnológica (instrumental) nos cursos de Educação Física, quer seja na forma como os currículos estão estruturados, ou no fazer pedagógico dos docentes. Palma (2001, p. 15) salienta que esta área do conhecimento, historicamente, tem-se fixado, quase de modo exclusivo, na técnica, no saber-fazer e no saber-ensinar, enquanto que o "[...] aprender a aprender ficou sem espaço".

Kincheloe (1997) afirma que o paradigma dominante, presente na formação inicial e continuada de professores, considera perigoso contextualizar o processo cultural - social no qual estamos imersos, porque o risco de se despersonalizar a culpa seria muito grande, inocentando maus alunos e colocando em perigo o profissionalismo do professor. Além do que, também seria um risco romper com as crenças, concepções, valores que estão presentes, mesmo que de forma velada, na maneira como se dá a formação profissional na atualidade, pois, mesmo para os mais críticos, o desconhecido causa um certo temor. Como as idéias novas podem causar mudanças, mas são incertas, é mais fácil fazer como sempre fizemos. No entanto, é mais perigoso, porque foram as velhas idéias que nos trouxeram onde estamos e, se não mudarmos, serão elas que nos levarão ao futuro.

Nessa direção, os docentes que possuem uma visão crítica e progressista de educação e formação profissional parecem conviver com um constante mal-estar em função dessa realidade que está

Movimento, Porto Alegre, v. 14, n. 03, p. 185-207, setembro/dezembro de 2008. 
posta e buscam soluções para romper com o paradigma hegemônico. Entre eles, parece haver um consenso de que mudanças são necessárias, já que, o que é impossível hoje, pode ser o padrão de amanhã. O desafio é estar pronto para intervir na realidade, mesmo sabendo que existem possibilidades e limites para que isso aconteça. O prêmio para tal ousadia será ser pioneiro de uma nova realidade.

Genericamente, os paradigmas, no caso, o paradigma tecnológico presente na formação profissional em Educação Física, filtram as possibilidades de mudanças porque existem regras e regulamentos (presentes no quadro paradigmático da área) que impedem a mudança no foco de observação. Como resultado disso, o que nos parece óbvio está relacionado ao paradigma vigente e, nesse caso, para que haja mudanças de fato, é preciso que antes de qualquer coisa rompamos com ele. É necessário quebrar os laços com o paradigma vigente, rumo a uma nova epistemologia para a formação de professores, de modo a, quem sabe, podermos visualizar uma sociedade mais participativa e dona de sua história.

A partir do exposto, centramos nossas reflexões na problemática apontada, qual seja, na dificuldade de romper com o paradigma técnico-instrumental e dominante, rumo a uma nova epistemologia para a formação inicial em Educação Física e, conseqüentemente, a dificuldade que os futuros professores terão em ensinar os componentes curriculares da área em nossas escolas. Elegemos, para guiar nosso estudo, a questão: devemos ou não ter uma nova epistemologia para a formação inicial de professores em Educação Física?

Certos de que estas questões exigiriam um esforço para além dos limites de um artigo, a seguir apresentaremos temas que entendemos poder ajudar na busca de respostas e na compreensão desta discussão. Iniciamos pela reflexão sobre o processo de proletarização do ensino que alimenta a dificuldade em se romper com o paradigma dominante na educação e na Educação Física. Após, buscamos compreender a necessidade de mudanças e, por fim, as possibilidades de uma prática reflexiva no trato com o conhecimento na formação de professores. Estes aspectos sinalizam para discussões acerca do momento educacional que estamos vivendo no sentido de se garantir avanços e não retrocessos.

Movimento, Porto Alegre, v. 14, n. 03, p. 185-207, setembro/dezembro de 2008. 


\section{SITUANDO O PROCESSO DE PROLETARIZAÇÃO DO ENSINO NA FORMAÇÃO INICIAL EM EDUCAÇÃO FÍSICA}

A formação profissional aparece como um importante meio de garantir aos professores o acesso à produção do conhecimento, dando aos futuros professores sustentação teórico-prática. E, assim, a urgência de uma formação de qualidade, que garanta a democratização do conhecimento, é reconhecida por todas as áreas (educacional, empresarial, etc.), bem como a necessidade de garantir a autonomia na busca e na produção do mesmo.

Com o intuito de intervir na realidade da complexa temática que é a formação de professores, pesquisadores de vários países têm tentado contribuir apresentando relatórios diagnósticos da situação insatisfatória dos sistemas de formação de professores e elaborando propostas de atuações, de reformas educativas (PÉREZ GÓMEZ, 1992). Entre eles, podemos elencar alguns estudiosos dos Estados Unidos da América, como Donald Schön, Thomaz S. Popkewitz e Kenneth Zeichner; da Espanha, Angel Pérez Gómez e Carlos Marcelo García; e, de Portugal, Antônio Nóvoa e Isabel Alarcão, entre outros. Estes analisam a forte tendência dos cursos de licenciatura formarem professores despreparados para lidar com a maioria das situações que acontecem na prática docente, pois recebem uma formação instrumentalizadora e permeada pela racionalidade técnica. Desta forma, os futuros professores não são preparados para terem autonomia quanto à aquisição e produção de conhecimento e, muito menos, em como lidar com ele na prática docente.

A racionalidade técnica ou tecnológica discutida neste texto é entendida por Habermas (1968) como uma forma de pensamento presente, principalmente no Ocidente, e fundamentada na filosofia positivista. Esta ganhou força com o advento da indústria moderna e, de acordo com Santomé (1998), Fernández Enguita (1989), Hipólito (1991), entre outros, tem como principais características (na instituição escolar e formação de professores): a fragmentação do conhecimento, a segmentação entre teoria e prática, a visão linearizada dada às tarefas de ensino e aos processos de aprendizagem, as concepções de ensino como processo de preparação técnica e a prática como

Movimento, Porto Alegre, v. 14, n. 03, p. 185-207, setembro/dezembro de 2008. 
um processo técnico de intervenção. Este é o modelo de educação que tem estado presente em nossas escolas e instituições formadoras ainda hoje.

Na formação do professor de Educação Fsica não é diferente, uma vez que o trato com essa área de conhecimento, na formação inicial, também responde ao modelo de racionalidade técnica. Aponta para uma tradição instrumentalizadora e, de maneira geral, tem contribuído para a perpetuação da crise na educação em todos os seus níveis de ensino.

Um aspecto da crise na educação relacionado com a influência da racionalidade técnica e discutido por estudiosos como Fernández Enguita (1991), Aplle, Teitelbaun (1991), Orza, Lawn (1991), Wenzel (1994), Hipólito (1997), entre outros, diz respeito aos reflexos desta influência para o profissional docente. Isto porque, a exemplo de outros profissionais no decorrer da história, os professores foram expropriados dos saberes. O mesmo seria dizer que sofreram e sofrem um processo de proletarização e desqualificação profissional.

Para esses autores, a tese da proletarização ${ }^{1}$ ancora-se no fato do professor ter passado a ser assalariado e de ter deixado de ser um profissional individual para ser um trabalhador coletivo a partir das relações capitalistas de produção. Essa nova condição de trabalho levou o professor a um processo de desqualificação que significa perda de controle sobre o processo do trabalho, bem como perda de prestígio social.

De acordo com Hipólito (1997, p. 85), o professor, pela ótica da tese da proletarização, "[...] passa por um processo de formação profissional numa instituição (agência formadora) que lhe fornece um determinado instrumental constituído por disciplinas (conteúdos) e metodologias (formas de transmissão)". Esta agência procurou fornecer tudo que acreditava ser necessário para que o futuro professor tivesse um bom desempenho em sua atuação. A partir dessa formação inicial, ingressa no mercado de trabalho, ou melhor, em

\footnotetext{
${ }^{1}$ Não trataremos de todos os aspectos referentes à Tese da Proletarização devido à amplitude do tema e por acreditarmos que não é necessário para o estudo aqui desenvolvido. Apenas serão discutidos os pontos que têm relação direta com o mesmo.
}

Movimento, Porto Alegre, v. 14, n. 03, p. 185-207, setembro/dezembro de 2008. 
uma segunda agência de formação, que é a escola. "Esta já está organizada a partir de um determinado processo de trabalho que define e conforma o trabalho escolar que ali vai se realizar (programas, tipo de trabalho, avaliação etc.)" (HIPÓLITO, 1997, p. 85). Aí o docente percebe que, ao vender sua força de trabalho (assalariado), submete-se a um processo de trabalho que foi previamente estabelecido e, por isso, a prática docente não depende mais, exclusivamente, da vontade individual do professor. Este tipo de organização escolar traz algumas conseqüências para a profissão de professor que também são comuns aos trabalhadores de outros setores sociais.

De acordo com Fernández Enguita (1991), Aplle, Teitelbaun (1991), Orza, Lawn (1991), Wenzel (1994), Hipólito (1997), entre outros, uma delas é a separação entre concepção e execução, pois os professores perdem o direito de controlar e planejar o trabalho, fazendo com que quase passem a ser apenas meros executores de tarefas e, o que é pior, não se importarem com esta situação, assumindo uma posição de comodismo. A característica deste tipo de organização de trabalho gera uma segunda conseqüência: a desqualificação profissional dos professores.

Na realidade, ao ingressar no mercado de trabalho, o professor tem um choque com o quadro que se apresenta. Durante a sua formação inicial, recebeu todo conhecimento que deveria ser necessário para desempenhar sua função docente, entretanto, a prática não é exatamente o que ele esperava. Passa a observar que não tem completo controle sobre o seu trabalho devido à racionalização do trabalho escolar e que, quanto mais complexas forem as formas de organização escolar, maior será o controle sobre o trabalho docente (HIPÓLITO, 1997).

De acordo com Fernández Enguita (1991), com a perda de autonomia e de possibilidades de tomar de decisões, o professor já não necessita dos conhecimentos e habilidades para fazê-los. Dessa forma, a desqualificação profissional e a possibilidade de expropriação dos saberes são reforçadas com a divisão do trabalho docente. Salienta, ainda, que, na prática, esta realidade pode ser visualizada, em primeiro lugar, por meio "[...] da proliferação de especialidades e o confinamento dos docentes em áreas e disciplinas" (ENGUITA,

Movimento, Porto Alegre, v. 14, n. 03, p. 185-207, setembro/dezembro de 2008. 
1991, p. 48) e, em segundo, pela “[...] delimitação de funções que são atribuídas de forma separada a trabalhadores específicos". É o caso da orientação, da educação especial, do atendimento psicológico e das diferentes disciplinas, como a Educação Física, dentre outras.

Sendo assim, de acordo com Wenzel (1994), o docente tende a deslocar cada vez mais suas responsabilidades para as figuras do diretor, coordenador, psicólogo, etc. e procura cada vez menos pensar o processo de concepção, produção do ensino, desligando-se das questões de fundo filosófico, sociológico e histórico.

Nesse sentido, a organização escolar colabora para o processo de desqualificação profissional, uma vez que tira do professor determinadas funções e as transfere para outros profissionais que trabalham na mesma instituição. Portanto, a responsabilidade da perda de autonomia e da qualidade da atuação do profissional não é exclusiva do professor. É o sistema que desencadeia este processo.

Outro aspecto que merece destaque é que, em conseqüência do modelo de organização escolar vigente, as exigências quanto à formação do professor vão sendo progressivamente reduzidas. Haja vista que, com a organização da prática pedagógica sob a forma de divisão do trabalho, não existe a necessidade que ele venha a conceber o trabalho, posto que apenas deverá obedecer a uma organização imposta. Também não há a necessidade de habilitação no que se refere à dimensão intelectual do seu trabalho, pois de uma forma ou de outra se tornará um alienado. Desse modo, a educação dos professores tem servido para enculturá-los e desqualificá-los.

A redução do universo de conhecimento também está presente no ensino superior, com a predominante presença de conteúdos técnicos e científicos e com a forma como as disciplinas estão organizadas, fragmentando o conhecimento e não permitindo que os futuros professores pensem, reflitam e façam suas análises críticas sobre os mesmos, nem os relacionem com sua prática profissional. A história de vida do futuro professor não é levada em consideração e, de acordo com Palma (2001, p. 11), tem-se a visão de que “[...] o aluno é uma folha em branco, uma tábula rasa a ser modelada. Ressalta-se, também, a importância dada ao que é avaliado, colocando o foco

Movimento, Porto Alegre, v. 14, n. 03, p. 185-207, setembro/dezembro de 2008. 
para a explicação das formas de conhecimentos que podem ser medidos". Torna-se evidente que a formação humana fica em segundo plano.

Respaldados nas considerações apresentadas, percebemos que o professor, na medida em que se torna um trabalhador coletivo, submete-se a um processo de desqualificação profissional e de expropriação do conhecimento, perdendo o controle total do processo, ou melhor, deixando de conceber o seu trabalho.

Em conseqüência, o professor não perde apenas o controle sobre o seu próprio trabalho, mas também os meios para buscar romper com o sistema vigente rumo a uma prática transformadora. Um dos fatores que provoca esta situação é a presença da racionalidade técnica na educação em todos os seus níveis de ensino, inclusive no ensino superior. Dessa forma, a maioria dos cursos de formação de professores tem contribuído para a perpetuação das relações sociais ora encontradas e tem preparado professores para uma prática reprodutivista e não transformadora.

Entendemos como necessário e urgente repensar a formação do professor de Educação Física, com vistas a formar profissionais que sejam capazes de compreender a complexidade das realidades sociais nas quais estamos envolvidos e contribuir para a sua transformação, para que os mesmos sejam produtores, transformadores, co-criadores e não reprodutores de saberes. Julgamos que, para que isso aconteça, um dos caminhos seria a superação do modelo de racionalidade técnica presente na educação em todos os seus níveis de ensino e na formação inicial rumo a uma nova epistemologia da prática docente.

\section{TRATO COM O CONHECIMENTO NA FORMAÇÃO INICIAL: A NECESSIDADE DE MUDANÇAS}

$\mathrm{Na}$ atualidade, poderíamos elencar muitos estudos, desenvolvidos em vários países, que discutem a formação inicial de professores organizada no modelo de racionalidade técnica ou instrumental. No entanto, mencionamos os que acreditamos serem os principais: dos

Movimento, Porto Alegre, v. 14, n. 03, p. 185-207, setembro/dezembro de 2008. 
Estados Unidos da América, os estudos realizados por Donald Schön, Thomaz S. Popkewitz e Kenneth Zeichner; da Espanha, os estudos de Angel Pérez Gómez e Carlos Marcelo García; e de Portugal, os estudos de Antônio Nóvoa e Isabel Alarcão. Estes analisam a forte tendência dos cursos de licenciatura formarem professores/profissionais que venham a se conformar com o sistema produtivo e servir ao capital e, desta forma, exercerem no futuro uma prática reprodutivista, sem compromisso político no sentido de transformação social.

Não obstante, parece-nos claro que a abordagem unilateral e positivista da ciência, nos moldes da racionalidade técnica, tem utilidade bastante limitada em qualquer que seja a prática social, como no caso da atuação do professor que é chamado a enfrentar problemas de grande complexidade e incerteza. Pérez Gómez (1992) afirma que não se deve conceber a prática educativa apenas como atividade técnica, uma vez que é, também e prioritariamente, uma atividade reflexiva e artística, na qual, em algumas situações, cabem algumas aplicações de caráter técnico.

Ao entender que a identidade da área do professor de Educação Física é de intervenção social, acreditamos que o conhecimento instrumental não deva ser priorizado, apesar de ter sua importância. Os maiores problemas a serem enfrentados na prática docente não são os que se apresentam bem definidos e com metas consensuais, mas aqueles que, ao contrário, apresentam-se incertos, únicos, variáveis, complexos e portadores de conflitos de valores. Nesta situação, é a natureza da realidade que irá determinar as características dos procedimentos, das técnicas e dos métodos mais apropriados.

Sobre o assunto, Schön (2000, p. 17) explicita que, na prática pedagógica, "[...] a incerteza, a singularidade e os conflitos de valores - escapam aos cânones da racionalidade técnica". Isto porque, na atuação docente, o profissional encontrará situações que serão únicas e, portanto, não poderá lidar com elas simplesmente aplicando as técnicas que são derivadas do seu conhecimento profissional. Enfim, a maioria das situações da prática docente não pode ser resolvida como uma questão técnica, pois está carregada de juízo de valores. Confirma, ainda, que, em determinadas situações, o conhecimento científico resolve a natureza do problema a ser enfrentado, mas que

Movimento, Porto Alegre, v. 14, n. 03, p. 185-207, setembro/dezembro de 2008. 
existem outras situações em que este tipo de conhecimento não fornece o suporte necessário para seu enfrentamento. $\mathrm{O}$ autor compara essas situações a dois tipos de terrenos: o primeiro deles é firme e fica no alto, os problemas podem ser resolvidos por meio de teorias e técnicas baseadas em pesquisas; o segundo é pantanoso e cheio de irregularidades, sendo que os problemas são caóticos e confusos, devendo o professor empenhar-se pessoalmente para a solução dos mesmos. Ao professor, cabe a escolha de se dedicar apenas aos problemas mais fáceis e de menos importância, que se localizam no terreno alto, ou também descer ao pântano e buscar resolver os de mais relevância e de investigação menos rigorosa.

Contudo, para que o professor de Educação Física possa fazer a escolha de olhar para os dois tipos de terreno, a formação inicial deve ser repensada, reorganizada. Do contrário, ao escolher apenas a solução dos problemas que se localizam no terreno alto, o professor irá ter uma leitura deformada da realidade e contribuir para a reprodução da mesma. Schön (2000) apóia esta idéia quando afirma que a presença da racionalidade técnica nos cursos de formação ameaça a competência profissional porque privilegia os problemas instrumentais da prática que são menos relevantes.

Habermas (1982) acrescenta que o positivismo e, por conseqüência, a racionalidade técnica recusam a auto-reflexão e a reflexão do conhecimento ao assumir a submissão ao método que reduz a razão a simples técnica de investigação. A forma de reflexão própria da ciência proíbe qualquer reflexão que ultrapasse os limites da ciência e, qualquer conhecimento que não seja o da ciência, não tem relevância.

Como, então, os futuros profissionais de Educação Fsica, baseados em uma formação permeada pela racionalidade técnica, poderão desenvolver práticas pedagógicas para lidar com as situações que extrapolam os terrenos retos e sem sinuosidades se eles são moldados para não extrapolar os limites? Com esse tipo de formação, os futuros professores não são levados à reflexão de que as situações mais ricas e importantes se encontram justamente nos terrenos pantanosos que são úmidos e férteis devido ao fato de serem incertos,

Movimento, Porto Alegre, v. 14, n. 03, p. 185-207, setembro/dezembro de 2008. 
únicos, variáveis, complexos e portadores de conflitos de valores. O caminho é uma nova epistemologia para a prática docente na formação inicial em Educação Física.

\section{PoSSIBILIDADE DE TRATO COM O CONHECIMENTO NA FORMAÇÃO DE PROFESSORES: A PRÁTICA REFLEXIVA EM QUESTÃO}

Identificamos, nas últimas décadas do século passado, uma mudança nas investigações na área da formação de professores e, principalmente a partir da década de 90, conquistou espaço a epistemologia da prática reflexiva, que tem em Schön (1992) uma fonte teórica comum. Esta tem sido discutida por autores como Zeichner (1992, 1993), Pérez Gómez (1992), Alarcão (2001) e contribuído significativamente para o avanço das práticas formadoras. Tem apontado para a necessidade de romper com o modelo de racionalidade técnica na formação inicial de professores e lança mão de uma prática docente com atitude de reflexão sobre essa mesma prática, antes, durante e depois da mesma, buscando elementos que auxiliem a melhorá-la.

As raízes dos estudos sobre o professor reflexivo e a formação reflexiva de professores remontam a Dewey (1859-1952). Zeichner (1993, p. 17), ao abordar as origens do termo prática reflexiva nos Estados Unidos da América, evidencia que, no início do século passado, John Dewey "[...] fez uma importante distinção entre o ato humano que é reflexivo e o que é rotina. Grande parte do que Dewey disse sobre este assunto foi dirigido aos professores e continua relevante nos anos noventa" do século XX. Dewey apresenta o conceito de pensamento reflexivo e suas implicações na prática pedagógica na obra How we think, escrita no período de 1896 a 1903 e publicado no ano de 1933, transformando-se em referência para os autores que propõem a prática reflexiva docente. Em português, a obra foi publicada no ano de 1953.

Percebemos que Dewey (1953, p. 85) compreende o pensamento reflexivo como uma forma mais complexa de pensar, a qual exige um processo investigativo, valorizando-se os meios para solucionar um problema. Por essa razão, o autor ratifica a necessidade

Movimento, Porto Alegre, v. 14, n. 03, p. 185-207, setembro/dezembro de 2008. 
de educar o pensamento, declarando que "[...] o espírito bem educado é aquele que, em cada caso especial, sabe melhor calcular a dose necessária de observações, de idéias, raciocínios, de experiência e o que mais se aproveita dos erros passados para, no futuro, saber refletir melhor". A partir do pensamento de Dewey sobre a distinção entre o ato de pensar ao acaso e o pensamento reflexivo, do ensino reflexivo fundamentado na problematização e de sua importância para o aprendizado, é possível compreender o sentido inicial atribuído à prática reflexiva.

Ainda é importante salientar que, além de Dewey, Schön (1992) informa que esse movimento em torno da formação reflexiva pode ser buscado em Montessori (1870-1952), Tolstoi (1828-1910), Froebel (1782-1852), Pestalozzi (1746-1827) e mesmo no Emílio, de Rousseau (1712-1778), que se encontra no centro de um conflito epistemológico.

Outra importante contribuição ao movimento em torno da prática reflexiva está nas críticas de Jürgen Habermas (1968) ao positivismo e à racionalidade técnica, pois o autor afirma que esta racionalidade recusa a auto-reflexão e a reflexão. Ressalta que, por estarmos conscientes das inadequações da racionalidade técnica, precisamos nos tornar capazes de usar facetas mais humanas e criativas de nós próprios em todas as profissões. Também por essa razão, os autores que defendem a epistemologia da prática reflexiva concordam com a posição crítica de Habermas diante desta questão e fundamentam a teoria na ação reflexiva, tendo a reflexão como ponto de partida e de chegada.

Pimenta (2002) afirma que, no Brasil, as contribuições relativas ao conceito do professor reflexivo, trazidas por autores estrangeiros nos anos de 1990, como Schön (1992, 2000), Pérez Gómez (1992), Zeichner (1992, 1993), Marcelo García (1999), Elliott (1994), Nóvoa (1992), entre outros, foram acolhidas porque traziam perspectivas para a reinvenção da escola democrática.

Lüdke et al. (2001, p. 12) acrescentam que é muito provável que a idéia tenha sido aceita com sucesso "[...] talvez porque correspondesse a um anseio natural à época, por saídas que permitissem retirar o professor de uma posição quase irremediavelmente

Movimento, Porto Alegre, v. 14, n. 03, p. 185-207, setembro/dezembro de 2008. 
passiva, na qual o havia enquadrado a Teoria da Reprodução, na década anterior". Entretanto, o sucesso do conceito da prática reflexiva foi tamanho que acabou provocando casos de desconexão, de usos inteiramente esvaziados ou até opostos ao sentido original da proposta. Esta realidade vem suscitando críticas à apropriação generalizada que o conceito de professor reflexivo permite.

De acordo com Pimenta (2002), as críticas dirigidas à prática reflexiva proposta por Schön $(1992,2000)$ relacionam-se com a supervalorização do professor como indivíduo, com a construção do saber docente somente a partir da prática, com o caráter individualista da reflexão e com o aspecto reducionista de sua utilização quando entendido de maneira a ignorar o contexto social em que esta prática se insere. Por outro lado, a mesma autora reconhece que a prática reflexiva tem se instituído como uma "[...] tendência significativa nas pesquisas em educação, apontando para a valorização dos processos de produção do saber docente a partir da prática e situando a pesquisa como instrumento de formação de professores" (PIMENTA, 2002 , p. 22), na qual o ensino é o ponto de partida e de chegada na pesquisa.

Nesse sentido, por valorizar as contribuições trazidas pela origem da proposta de Schön e, por haver consenso na necessidade de avançar com esta idéia, diferentes propostas de trabalho têm sido apresentadas, entre elas estão as de Nóvoa (1992), Zeichner (1992, 1993), Pérez Gómez (1992, 2001), Giroux (1997), Gimeno Sacristán, Pérez Gómez (1998), Marcelo Garcia (1999), Alarcão (2001, 2003), Tardif (2002), Pimenta (2002), Contreras (2002), entre outros.

Consideramos que estas propostas têm significância, uma vez que apontam possibilidades de trato com o conhecimento na formação inicial. E, buscando compreender o contexto das práticas pedagógicas nesse período de formação, procuramos perspectivas de análise referentes à reflexão crítica em diferentes autores, com vistas a não perder a dialeticidade da reflexão durante a prática educativa que compreende, entre outras ações, a de ensinar conhecimentos.

Referindo-se ao modelo de formação de professores como artistas reflexivos, Pérez Goméz (1992) assegura que a epistemologia

Movimento, Porto Alegre, v. 14, n. 03, p. 185-207, setembro/dezembro de 2008. 
da prática reflexiva apresenta-se como uma proposta de ensino prático reflexivo para a formação profissional, em que as experiências práticas de ensino, visando o conhecimento na ação, estão presentes desde a preparação inicial, mediada pela reflexão-na-ação, reflexãosobre-a-ação e reflexão-sobre-a-reflexão-na-ação. Nesse modelo, a prática reflexiva passa a ser o eixo do currículo da formação do professor e deve promover o desenvolvimento de "[...] capacidades, conhecimentos e atitudes que não dependem da assimilação do conhecimento acadêmico, mas sim da mobilização de um outro tipo de conhecimento produzido em diálogo com a situação real" (GIMENO SACRISTÁN; PÉREZ GÓMEZ, 1998, p. 21), além de desenvolver a dialeticidade da reflexão de como fazer uso do conhecimento nas situações que se apresentam na prática pedagógica. Para isso, o professor deve exercer uma "[...] mediação crítica da utilização do conhecimento" (GIMENO SACRISTÁN; PÉREZ GÓMEZ, 1998, p. 21).

De acordo com Pimenta (2002, p. 26), o conhecimento, a teoria como cultura objetivada, além de seu papel formativo, permitirá que os futuros professores tenham uma ação contextualizada a partir do momento em que os saberes teóricos se articulam com os saberes da prática, "[...] ao mesmo tempo ressignificando-os e sendo por eles ressignificados". Desse modo, o papel da teoria é oferecer " $[$... $]$ perspectivas de análise para compreenderem os contextos históricos, sociais, culturais, organizacionais e de si mesmos como profissionais, nos quais se dá sua atividade docente, para neles intervir, transformando-os" (PIMENTA, 2002, p. 26). Daí a importância de se repensar os conhecimentos necessários à atuação docente porque, ao permitir a aquisição de um corpo de conhecimento, estaremos promovendo a possibilidade de construção de outros conhecimentos com base em uma prática crítica e reflexiva na qual o futuro professor possa adquirir autonomia.

Sobre o assunto, Tardif (2002) argumenta que, embora a formação inicial esteja organizada por disciplinas constituídas de conhecimentos que, na maioria das vezes, estão mal enraizados na ação cotidiana, não é preciso esvaziar a lógica disciplinar dos programas de formação, mas sim abrir um espaço maior para uma lógica de

Movimento, Porto Alegre, v. 14, n. 03, p. 185-207, setembro/dezembro de 2008. 
formação profissional que "[...] reconheça os alunos como sujeitos do conhecimento e não simplesmente como espíritos virgens aos quais nos limitamos a fornecer conhecimentos disciplinares e informações procedimentais [...]" (TARDIF, 2002, p. 242). Esta lógica deve proceder por meio de um enfoque reflexivo ao levar em conta as condições reais do trabalho docente.

Com isso, acreditamos que não podemos correr o risco do esvaziamento do conhecimento, não devemos descartar todos os saberes que foram historicamente produzidos e nem valorizar apenas a prática pela prática, porque assim estaríamos contribuindo para um processo de desqualificação profissional em Educação Física.

Em se tratando de como proceder pedagogicamente no processo de formação inicial, Zeichner (1993) reconhece na formação reflexiva uma estratégia para melhorar a formação de professores porque pode possibilitar um aumento na capacidade de enfrentamento da complexidade da prática docente. Mas adverte que o ensino deve acontecer como atividade crítica, valendo-se da reflexão da prática, para que haja uma reconstrução social. O contexto social e institucional, no qual o ensino está inserido, não pode ser ignorado. Nesse sentido, a reflexão só pode se realizar no coletivo, em comunidades de aprendizagem nas quais os professores se apóiem e se estimulem mutuamente, com vistas à construção de sociedades mais humanas.

Giroux (1997), ao apresentar os limites da proposta de Schön, desenvolve a concepção do professor como intelectual crítico. Nesta, a reflexão é coletiva e os professores precisam desenvolver um discurso que una a linguagem da crítica com a possibilidade de promover mudanças, dando o claro sentido à reflexão de um compromisso emancipatório de transformação das desigualdades sociais dentro e fora da escola. Afirma, ainda, que devem ser dadas aos alunos " [...] a oportunidade de tornarem-se cidadãos que tenham conhecimento e coragem para lutar a fim de que o desespero não seja convincente e a esperança seja viável" (GIROUX, 1997, p. 163), valorizando a aquisição de conhecimentos historicamente produzidos. Com esta proposta de trabalho, o autor pretende criticar, teoricamente, as ideologias tecnocráticas e instrumentais presentes em muitas teorias educacionais e valorizadas no ensino superior, as quais separam “ " [...]

Movimento, Porto Alegre, v. 14, n. 03, p. 185-207, setembro/dezembro de 2008. 
conceitualização, planejamento e organização curricular dos processos de implementação e execução" (GIROUX, 1997, p. 161). Busca, com esta discussão, romper com o processo de proletarização e desqualificação profissional que tem presença marcante no ensino superior.

Contreras (2002), em crítica à concepção reflexiva de Schön, oferece resistência à idéia de que a reflexão por si só possibilita a compreensão dos fatores sociais e institucionais que interferem na prática docente. Ao mesmo tempo, aponta que Giroux não sinaliza como os professores podem realizar a transição de técnicos reprodutores e reflexivos individualmente para intelectuais críticos e transformadores. Desse modo, propõe o modelo de profissionais como intelectuais críticos que participam de um esforço para compreender os fatores sociais e institucionais que estão ocultos na prática educativa e que a afetam, pois as ações não são espontâneas e muito menos naturais, são descobertas cotidianas. Para este autor, somente neste modelo, a reflexão tem significância para a prática docente.

Pimenta (2002, p. 39), ao reconhecer a quantidade e a velocidade das informações na sociedade de hoje, postula que um profissional precisa estar preparado "[...] científica, técnica, tecnológica, pedagógica, cultural e humanamente [...]" e deve ser "[...] um profissional que reflete sobre o seu fazer pesquisando-o nos contextos nos quais ocorre". Para tanto, ao assumir que a atividade docente é práxis, afirma que o professor deve ser visto como um intelectual que está sempre em formação e que a educação é um processo dialético no qual o homem se desenvolve historicamente. Propõe que a identidade do profissional docente deve superar o papel de "[...] professores reflexivos para o de intelectuais críticos e reflexivos" (PIMENTA, 2002, p. 47).

Nesta perspectiva, é necessário preparar os futuros professores para serem promotores do seu próprio desenvolvimento profissional e, para isso, os autores que defendem a epistemologia da prática reflexiva ressaltam a necessidade de desenvolver a capacidade reflexiva e investigativa do professor, para que assim possam entender a complexidade que envolve a prática educacional. Desse modo, a formação inicial em Educação Física precisa ter uma organização

Movimento, Porto Alegre, v. 14, n. 03, p. 185-207, setembro/dezembro de 2008. 
curricular que permita a apropriação dos conhecimentos necessários por meio do conhecimento-na-ação proposto por Schön (2000) e da investigação-ação (ELLIOTT, 1994, 1998), que levam o professor ao auto-conhecimento.

A investigação na ação ou pesquisa-ação, proposta por Elliott (1994, 1998), possibilita que, durante a formação inicial do professor de Educação Física, as ações humanas e as situações sociais sejam experimentadas pelos alunos/acadêmicos. Tomando-se por base esse referencial teórico-metodológico, a formação passa pela experimentação, pela inovação, pelo ensaio de novos métodos de trabalho, por uma reflexão crítica sobre a sua utilização. De acordo com Nóvoa (1992), passa, também, por processos de formação diretamente articulados com as práticas educativas que levam os futuros professores à produção de saberes pertinentes à prática docente.

Preocupamo-nos em buscar garantir, na formação inicial, os saberes necessários à atuação docente. Para tanto, entendemos que é preciso o desenvolvimento da competência técnica desde que ela esteja articulada com as situações que ocorrem no cotidiano docente. Um dos caminhos a ser utilizado para a conquista da mesma é a investigação na ação (ELLIOTT, 1994) por meio do desenvolvimento do practicum (ZEICHNER, 1993) e não durante situações simuladas, visto que a relevância da competência técnica só será consolidada se puder ser levada com êxito aos espaços de atuação do profissional da área por meio da problematização e da busca de solução de problemas.

Para que isso possa acontecer de modo efetivo, o futuro professor de Educação Física deve ser preparado para enfrentar e refletir, criticamente, sobre os fenômenos e as situações conflituosas presentes na Educação Física escolar. Por isso, os cursos precisam estabelecer estreita relação com a escola para que uma formação mais condizente com a prática docente venha, de fato, concretizar-se.

Outro aspecto contemplado nas novas orientações para os cursos de licenciatura é que as práticas pedagógicas devem estar presentes desde os primeiros anos da formação inicial e o estágio supervisionado na segunda metade. Sua presença colabora para que a formação

Movimento, Porto Alegre, v. 14, n. 03, p. 185-207, setembro/dezembro de 2008. 
do professor possa ser pautada pela prática crítica e reflexiva desde o início do curso. Nesse sentido, as contribuições trazidas por Schön $(1992,2000)$ e acrescidas por outros autores devem ser possibilitadas durante as experiências da prática de ensino de forma que o futuro professor seja preparado para a adoção de uma prática crítica e reflexiva que se estenda durante a sua atuação docente. Isto com certeza contribuirá para que os futuros professores tenham maiores condições de superar os conflitos presentes no desenvolvimento da prática pedagógica. O ideal seria que esta possibilidade de trato com o conhecimento não ficasse restrita apenas a algumas disciplinas, pois não cabe apenas ao professor da disciplina de estágio supervisionado conhecer a escola.

Nesta direção, Zeichner (1993, p. 14) acrescenta que o practicum reflexivo, que se caracteriza pela investigação mediada pela prática reflexiva, deve ser um dos "[...] momentos estruturados de prática pedagógica, integrados nos programas de formação de professores". Nesta perspectiva, o practicum, como proposta metodológica, viria contribuir para promover a interação entre teoria e prática, entre saber e saber fazer e se consolidar como uma possibilidade de romper com a fragmentação do conhecimento presente na formação inicial de Educação Física, o que aproximaria os futuros professores da realidade de sua atuação docente.

De acordo com os autores que defendem a epistemologia da prática reflexiva, e entre eles Zeichner (1993), a reflexão no processo de formação profissional não deve ser vista como um conjunto de técnicas, como uma receita. É preciso que se constitua em um processo de pensamento, de análise e interpretação e que ocorra antes, durante e depois da ação, exigindo uma preparação para a adoção da prática reflexiva. Para que isto ocorra, é importante que essa nova epistemologia da prática esteja presente em todos os momentos da formação profissional.

Em síntese, apontamos, neste estudo, a necessidade de uma formação profissional em Educação Física que atente para a formação crítica e reflexiva. E é por isso que apresentamos a discussão acerca de uma prática pedagógica que esteja em alerta para o valor da epistemologia da prática reflexiva.

Movimento, Porto Alegre, v. 14, n. 03, p. 185-207, setembro/dezembro de 2008. 


\section{CONSIDERAÇÕES FINAIS}

$\mathrm{O}$ ato de ensinar encerra em si mesmo posições antagônicas. Pode ser, ao mesmo tempo, enriquecedor e repressor. Como afirmam Freire e Brito (1987, p. 35), “[...] para conhecer o mundo e a reserva cultural acumulada pela experiência da humanidade, não há necessidade de nos desconhecer e de impedir a expressão de nossa originalidade". É só no ato de aprender que precisamos "[...] desaprender certas coisas, ou seja, nos livrarmos daquilo que nos ensinaram a fazer e a pensar em detrimento da expressão livre da espontaneidade" (FREIRE; BRITO, 1987, p. 35).

Ao tratar de um mesmo conhecimento, podemos ter um professor que trabalhe de maneira ordenadamente autoritária e outro que trabalhe dentro de uma ordem necessária. Podemos ter um professor que permita que seus alunos apenas conheçam e não aprendam e podemos ter um professor que favoreça seus alunos a conhecer e aprender. É por isso que pensar em como tratar o conhecimento na formação inicial em Educação Física é tarefa tão relevante. Afinal como assegura Pimenta (1999, p. 22), é preciso mais do que simplesmente informar a existência de um conhecimento, pois " [....] conhecer significa estar consciente do poder do conhecimento para a produção da via material, social e existencial da humanidade".

Para que possamos ter uma prática pedagógica que permita desenvolver autonomia e criatividade nos alunos, precisamos romper com relações autoritárias. Isto significa que o mais importante é ensinar estes professores a estudar, a pesquisar e a ensinar, ajudando-os a desenvolver sua capacidade crítica e conduzindo-os a saberem o que fazer com o conhecimento. Os futuros professores só saberão o valor dessa liberdade de 'aprender a saber' o que fazer com o conhecimento se puderem vivenciá-la na formação inicial em Educação Física. Isso evidencia que o papel do docente na formação inicial deve ser de mediador do conhecimento, no sentido de possibilitar aos futuros professores o desenvolvimento da reflexão.

Nesse sentido, Pérez Gómez (1992, p. 112-3) alerta que o docente responsável pela formação inicial "[...] deve ser capaz de actuar e de reflectir sobre a sua própria acção como formador. Deve perceber

Movimento, Porto Alegre, v. 14, n. 03, p. 185-207, setembro/dezembro de 2008. 
que a sua intervenção é uma prática de segunda ordem, um processo de diálogo reflexivo com o aluno-mestre sobre as situações educativas". Nessa direção, tomamos a formação inicial de professores como lugar onde os docentes não só ensinam, mas também aprendem. São, por isso, sujeitos reflexivos, pois se abrem perspectivas para refletir sobre a sua prática pedagógica.

Para que isso ocorra, o professor que forma o futuro professor deve, também, adotar uma prática reflexiva em seu trabalho pedagógico. É preciso que haja uma nova epistemologia da prática pedagógica no período de formação e que seja baseada em um referencial que possibilite este tipo de intervenção.

Movimento, Porto Alegre, v. 14, n. 03, p. 185-207, setembro/dezembro de 2008. 
Initial Formation in Physical Education: a New Epistemology of the Docent Practice.

Abstract: It was intended to reflect about the need of the docents that work in the formation of teacher of physical education, to rupture with the technical-instrumental paradigm, directing to a new epistemology of docent practice. Initially it was established a debate about the process of popularization of the schooling that feed the difficulty in rupture with the dominant paradigm present in the docent formation. After, it was tried to comprehend the need of changes and the possibilities of a reflexive practice in the tract with the knowledge in the docent formation.

Keywords: Faculty. Teaching. Knowledge.

Formación inicial en Educación Física: una nueva epistemologia de la práctica docente.

Resumen: Pretendemos reflectir sobre la necesidad de los docentes, que actuan en la formación de maestros en educación física, en romper con el paradigma técnico-instrumental, rumo a una nueva epistemologia de la práctica docente. Inicialmente establecemos un debate sobre el proceso de proletarización de el ensino que alimenta la dificultad en se romper con el paradigma dominante presente en la formación docente. Después, buscamos comprender la necesidad de mudanzas y las posibilidades de una práctica reflexiva en el tracto con el conocimiento en la formación de maestros.

Palabras-clave: Docentes. Ensenãnza. Conocimiento.

\section{REFERÊNCIAS}

ALARCÃO, I. Novas tendências nos paradigmas de investigação em educação. In: (Org.). Escola reflexiva e nova racionalidade. Porto Alegre: Artmed, 2001. p. 135-144.

Professores reflexivos em uma escola reflexiva. São Paulo: Cortez, 2003.

APLLE, M. W.; TEITELBAUN, K. Está o professorado perdendo o controle de suas qualificações e do currículo? Revista Teoria e Educação, Porto Alegre, n. 4, p. 62-73, 1991.

Movimento, Porto Alegre, v. 14, n. 03, p. 185-207, setembro/dezembro de 2008. 
BARBOSA-RINALDI, I. P.; MARTINELI, T. A. P. A produção do conhecimento em ginástica na formação profissional: oito anos de CONBRACE. In: CONGRESSO BRASILEIRO DE CIÊNCIAS DO ESPORTE, 13., 2003, Caxambu. Anais... Caxambu: [s.n.], 2003. 1 CD-ROM.

BETTI, M. Educação Física e sociedade. São Paulo: Movimento, 1991.

CONTRERAS, J. Autonomia de professores. São Paulo: Cortez, 2002.

DEWEY, J. Como pensamos. São Paulo: Editora Nacional, 1953.

ELLIOTT, J. La investigación-acción en educación. Madrid: Morata, 1994.

Recolocando a pesquisa-ação em seu lugar original e próprio. In: GERALDI, C. M. G.; FIORENTINI, D.; PEREIRA, E. M. de A. (Orgs.) Cartografias do trabalho docente: professor (a) - pesquisador (a). Campinas: Mercado das Letras/ALB, 1998. p. 137-152.

FERNÁNDEZ ENGUITA, M. A face oculta da escola. Porto Alegre: Artes Médicas, 1989.

FREIRE, R.; BRITO, F. Utopia e paixão: a política do cotidiano. 5. ed. Rio de Janeiro: Rocco, 1987.

GIMENO SACRISTÁN J.; PÉREZ GÓMEZ, A. I. Compreender e transformar o ensino. Porto Alegre: Artmed, 1998.

GIROUX, H. A. Os professores como intelectuais: rumo a uma pedagogia crítica da aprendizagem. Porto Alegre: Artes Médicas, 1997.

HABERMAS, J. Conhecimento e interesse. Rio de Janeiro: Zahar, 1982.

Técnica e ciência como 'ideologia'. Lisboa: Edições 70, 1968.

HIPÓLITO, Á. M. Processo de trabalho na escola: algumas categorias para análise. Revista Teoria e Educação, Porto Alegre, n. 4, p. 3-21, 1991.

Trabalho docente, classe social e relações de gênero. Campinas, São Paulo: Papirus, 1997.

KINCHELOE, J. L. A formação do professor como compromisso político: mapeando o pós-moderno. Porto Alegre: Artes Médicas, 1997.

MARCELO GARCÍA, C. Formação de professores para uma mudança educativa. Porto: Editora Porto, 1999.

MARTINELI, T. A. P. A formação inicial em educação física e a preparação de um profissional reflexivo. 2001. $300 \mathrm{fls}$. Dissertação (Mestrado) - Curso de Educação, Departamento de Teoria e Prática, UEM, Maringá, 2001.

MORIN, E. Os sete saberes necessários à educação do futuro. 4. ed. São Paulo: Cortez; Brasília, DF: UNESCO, 2001,

Movimento, Porto Alegre, v. 14, n. 03, p. 185-207, setembro/dezembro de 2008. 
NÓVOA, A. Formação de professores e profissão docente. In: NÓVOA, A. (Coord.). Os professores e sua formação. Lisboa: Dom Quixote, 1992. p. 9-33.

ORZA, J. ; L. M. O trabalho docente: interpretando o processo de trabalho do ensino. Revista Teoria e Educação, Porto Alegre, n. 4, p. 140-158, 1991.

PALMA, J. A. V. A educação continuada do professor de Educação Física: possibilitando práticas reflexivas. 2001. 96 f. Tese (Doutorado) - Curso de Educação Física, Faculdade de Educação Física, UNICAMP, Campinas, 2001.

PÉREZ GÓMEZ, A. I. O pensamento prático do professor: a formação do professor como profissional reflexivo. In: NÓVOA, A. (Org.). Os professores e sua formação. Lisboa: Dom Quixote, 1992. p. 93-114.

2001.

A cultura escolar na sociedade neoliberal. Porto Alegre: Artmed,

PIMENTA, S. G. Formação de professores: identidade e saberes da docência. In: (Org.). Saberes pedagógicos e atividade docente. São Paulo: Cortez, 1999. p. 17-52.

. Professor reflexivo: construindo uma crítica. In: PIMENTA, S. G. ; GHEDIN, E. (Orgs). Professor reflexivo no Brasil: gênese e crítica de um conceito. São Paulo: Cortez, 2002. p. 17-52.

RIBEIRO, D. M. D. B. A epistemologia da prática reflexiva na formação inicial do professor de educação física. 2003. 193 f. Dissertação (Mestrado) - Curso de Educação, Departamento de Teoria e Prática, UEM, Maringá, 2003.

SANTOMÉ, J. T. Globalização e interdisciplinaridade: o currículo integrado. Porto Alegre: Artes Médicas Sul, 1998.

SCHÖN, D. Formar professores como profissionais reflexivos. In: NÓVOA, A. (Org.). Os professores e sua formação. Lisboa: Dom Quixote, 1992. p. 77-91.

Educando o profissional reflexivo. Porto Alegre: Artmed, 2000.

TARDIF, M. Saberes docentes e formação profissional. Petrópolis, RJ: Vozes, 2002.

WENZEL, R. L. Professor: agente da educação? Campinas, SP: Papirus, 1994.

ZEICHNER, K. M. Novos caminhos para o practicum: uma perspectiva para os anos 90. In: NÓVOA, A. (Org.). Os professores e sua formação. Lisboa: Dom Quixote, 1992. p. 93-114. Educa, 1993

A formação reflexiva de professores: idéias e práticas. Lisboa:

Movimento, Porto Alegre, v. 14, n. 03, p. 185-207, setembro/dezembro de 2008. 